Check for updates

Cite this: RSC Adv., 2018, 8, 9311

Received 27th January 2018

Accepted 26th February 2018

DOI: $10.1039 / \mathrm{c} 8 \mathrm{ra00838h}$

rsc.li/rsc-advances

\section{Polymeric ionic liquid gels composed of hydrophilic and hydrophobic units for high adsorption selectivity of perrhenate $\uparrow$}

\author{
Dong Han, $\stackrel{t}{a}^{a}$ Xingxiao Li, $\stackrel{t}{a}^{a}$ Yu Cui, ${ }^{a}$ Xin Yang, ${ }^{a}$ Xibang Chen, ${ }^{a}$ Ling Xu, ${ }^{\text {bc }}$ Jing Peng, ${ }^{\text {*a }}$ \\ Jiuqiang $\mathrm{Li}^{\mathrm{a}}$ and Maolin Zhai (iD *a
}

\begin{abstract}
The removal of $\mathrm{TCO}_{4}{ }^{-}$from aqueous solutions has attracted more and more attention recently, and $\mathrm{ReO}_{4}{ }^{-}$ has been widely used as its natural analog. In this work, polymeric ionic liquid gel adsorbents, $\mathrm{PC}_{2}-\mathrm{C}_{12} \mathrm{vimBr}$, with high adsorption capacity and selectivity towards $\mathrm{ReO}_{4}{ }^{-}$were synthesized by radiation-induced polymerization and crosslinking. $\mathrm{PC}_{2}-\mathrm{C}_{12} \mathrm{vimBr}$ was composed of two monomers: a hydrophobic unit, 1vinyl-3-dodecylimidazolium bromide for high selectivity, and a hydrophilic unit, 1-vinyl-3ethylimidazolium bromide for improved kinetics. A gel fraction up to $90 \%$ could be achieved under 40 kGy with varied monomer ratios. The adsorption of $\mathrm{PC}_{2}-\mathrm{C}_{12} \mathrm{vimBr}$ gels for $\mathrm{ReO}_{4}{ }^{-}$was evaluated by batch adsorption. The $\mathrm{PC}_{2}-\mathrm{C}_{12} \mathrm{vimBr}$ gel containing $20 \mathrm{~mol} \%$ hydrophilic unit (named $\mathrm{PC}_{2}-\mathrm{C}_{12} \mathrm{vimBr}-\mathrm{A}$ ) could significantly improve the adsorption kinetics, which had an equilibrium time of ca. $24 \mathrm{~h}$. The adsorption capacity obtained from the Langmuir model was $559 \mathrm{mg} \mathrm{g}^{-1}$ (Re/gel). The selective factor against $\mathrm{NO}_{3}$ was $33.4 \pm 1.9$, which was more than 10 times higher than that of $\mathrm{PC}_{2} \mathrm{vimBr}$, and it could maintain $\mathrm{ReO}_{4}{ }^{-}$uptake as high as $100 \mathrm{mg} \mathrm{g}^{-1}$ in $0.5 \mathrm{~mol} \mathrm{~kg}{ }^{-1} \mathrm{HNO}_{3}$. The $\Delta \mathrm{H}^{\Theta}$ and $\Delta \mathrm{S}^{\Theta}$ of the $\mathrm{NO}_{3}{ }^{-} / \mathrm{ReO}_{4}{ }^{-}$ionexchange reaction of $\mathrm{PC}_{2}-\mathrm{C}_{12} \mathrm{VimNO}_{3}-\mathrm{A}$ were $-16.9 \mathrm{~kJ} \mathrm{~mol}{ }^{-1}$ and $29 \mathrm{~J} \mathrm{~mol}^{-1} \mathrm{~K}^{-1}$, respectively, indicating physical adsorption. The adsorption mechanism of $\mathrm{ReO}_{4}{ }^{-}$onto $\mathrm{PC}_{2}-\mathrm{C}_{12} \mathrm{vimBr}-\mathrm{A}$ gel was ionexchange, and it could be recovered using $5.4 \mathrm{~mol} \mathrm{~kg}^{-1} \mathrm{HNO}_{3}$.
\end{abstract}

\section{Introduction}

Technetium (Tc) is an artificial element, and all its isotopes are radioactive. A large amount of ${ }^{99} \mathrm{Tc}$ is produced from nuclear plants nowadays, and exists in high-level liquid waste. Since Tc is hazardous and has high mobility in the environment, and it may affect the geological disposal of other radioactive nuclei, the removal of Tc from aqueous solutions has attracted more and more attention recently. ${ }^{1}$ And because of the radioactivity of Tc, it is not allowed to be handled in the normal lab, and rhenium (Re) has been extensively used as its analog owing to their similar chemistry properties. ${ }^{1-3}$

Tc mainly exists in the form of $\mathrm{TcO}_{4}{ }^{-}$in the high-level waste. ${ }^{4}$ Many kinds of method to remove $\mathrm{TcO}_{4}{ }^{-}$and $\mathrm{ReO}_{4}{ }^{-}$have been

\footnotetext{
${ }^{a}$ Beijing National Laboratory for Molecular Sciences, Radiochemistry and Radiation Chemistry Key Laboratory of Fundamental Science, The Key Laboratory of Polymer Chemistry and Physics of the Ministry of Education, College of Chemistry and Molecular Engineering, Peking University, Beijing 100871, China. E-mail: jpeng@ pku.edu.cn; mlzhai@pku.edu.cn

${ }^{b}$ State Key Laboratory of Molecular Vaccinology and Molecular Diagnostics, School of Public Health, Xiamen University, Xiamen, Fujian 161102, China

'Peking University Shenzhen Institute, Shenzhen 518057, China

$\dagger$ Electronic supplementary information (ESI) available: IR, TGA, EA, and XPS of $\mathrm{PC}_{2}-\mathrm{C}_{12}$ vimBr. See DOI: $10.1039 / \mathrm{c} 8 \mathrm{ra00838h}$

$\$$ These authors contributed equally to this work.
}

investigated in recent years, including the reductive immobilization of $\mathrm{TcO}_{4}{ }^{-}$or $\mathrm{ReO}_{4}{ }^{-}$by $\mathrm{Fe}(0)^{5,6}$ and the direct adsorption by adsorbents. $^{7-10}$ Comparing to the reductive method, the adsorption takes the advantage of high adsorption capacity and the reusability of the adsorbents.

Most adsorbents towards $\mathrm{TcO}_{4}{ }^{-}$and $\mathrm{ReO}_{4}{ }^{-}$depended on ion-exchange. MOFs ${ }^{11-14}$ carbon materials, ${ }^{15-18}$ and organic adsorbents have been employed as the adsorbents. Organic adsorbents including resins, ${ }^{19,20}$ grafted materials ${ }^{21,22}$ and gels $^{23,24}$ take the advantage of high adsorption capacities and easy design and synthesis. Quaternary ammonium ${ }^{\mathbf{1 9 , 2 3}}$ including pyridinium ${ }^{25,26}$ and imidazolium ${ }^{3,21,27}$ have been used as the functional groups in many ion-exchange adsorbents. ${ }^{19}$ For the quaternary ammonium, alkyl has been widely used as the group on the quaternary $\mathrm{N}$ atom, including ethyl, propyl, butyl, pentyl, hexyl etc. ${ }^{28,29}$ And it was found that longer alkyl chain in quaternary ammonium may bring higher selectivity towards $\mathrm{ReO}_{4}{ }^{-28}$

However, adsorbents depending on ion-exchange would be influenced by the other anions in the solution as competitors, and a large amount of $\mathrm{NO}_{3}{ }^{-}$exists in the high-level liquid waste. So it is very important to develop adsorbents with high selectivities towards $\mathrm{TcO}_{4}{ }^{-}$or $\mathrm{ReO}_{4}{ }^{-}$. Wang et al. reported a $\mathrm{TcO}_{4}{ }^{-}$adsorbent, NDTB-1, with an adsorption capacity of $162.2 \mathrm{mg} \mathrm{g}^{-1}$ and a maximum distribution coefficient $K_{\mathrm{d}}$ of 
$1.0534 \times 10^{4} \mathrm{~mL} \mathrm{~g}^{-1} \cdot{ }^{10}$ Shu et al. developed a surface ionimprinted magnetic microsphere $\mathrm{ReO}_{4}{ }^{-}$adsorbent containing imidazolium groups with an adsorption capacity of $62.8 \mathrm{mg} \mathrm{g}^{-1}$ and a Langmuir constant of $1.35 \mathrm{~L} \mathrm{mg}^{-1} .^{3}$

On the other hand, some of the reported excellent adsorbents contain metal elements, e.g. Ag in SCU-100, ${ }^{13}$ which may result in the increase of radioactive wastes. Adsorbents composed of only $\mathrm{C}, \mathrm{H}, \mathrm{N}$, O may avoid the secondary radioactive waste since they follow the CHON principle. ${ }^{30,31}$ Organic adsorbents such as polymeric ionic liquids may meet this requirement.

Polymeric ionic liquid is a kind of polymer which contains ionic liquid units, and they have attracted much attention in many fields, such as polyelectrolytes, polymeric surfactants, anion sensitive smart materials, ${ }^{32,33}$ gas separation membranes, ${ }^{34}$ and also ion-exchange adsorbents. ${ }^{35}$ Recently we reported a polymeric ionic liquid gel $\mathrm{ReO}_{4}{ }^{-}$adsorbent with high adsorption capacity of $865 \mathrm{mg} \mathrm{g}^{-1}$, but the selectivity is not high enough, and we proposed that hydrophobic polycations might have higher selectivity towards $\mathrm{ReO}_{4}{ }^{-{ }^{24}}$ Polymers with both hydrophilic and hydrophobic segments have been reported with interesting selfassembling behaviors ${ }^{36}$ or as proton conductive membranes. ${ }^{37}$ Considering the advantages of combination of the hydrophilic and the hydrophobic segments in polymers, i.e. the hydrophobic one is favour for higher adsorption selectivity towards $\mathrm{ReO}_{4}{ }^{-}$and the hydrophilic one is better for adsorption kinetics, we herein developed a polymeric ionic liquid gel adsorbent, $\mathrm{PC}_{2}-\mathrm{C}_{12} \mathrm{VimBr}$, with high adsorption capacity and selectivity, which was synthesized easily by radiation-induced polymerization and crosslinking of 1-vinyl-3-alkylimidazolium. Considering longer alkyl chain on the quaternary $\mathrm{N}$ atom can increase the hydrophobicity of gels, which may result in higher adsorption selectivity towards $\mathrm{ReO}_{4}{ }^{-}$, a hydrophobic unit, 1-vinyl-3-dodecylimidazolium bromide $\left(\mathrm{C}_{12}\right.$ vimBr$)$ was chosen to improve the selectivity. On the other hand, a hydrophilic unit, 1-vinyl-3-ethylimidazolium bromide $\left(\mathrm{C}_{2} \mathrm{vimBr}\right)$, was chosen to improve the adsorption kinetics of $\mathrm{ReO}_{4}{ }^{-}$ in aqueous solution. A series of $\mathrm{PC}_{2}-\mathrm{C}_{12}$ vimBr gels with different molar ratio of hydrophobic and hydrophilic units were synthesized and characterized, and their adsorption kinetics towards $\mathrm{ReO}_{4}{ }^{-}$ were investigated. Then the adsorption isotherm, selectivity and mechanism of $\mathrm{PC}_{2}-\mathrm{C}_{12}$ vimBr gel were investigated in detail.

\section{Experimental}

\subsection{Materials}

$\mathrm{C}_{2}$ vimBr and $\mathrm{C}_{12}$ vimBr monomers were purchased from Lanzhou Greenchem ILs, LICP. CAS., dried in vacuum to remove the residual solvent. 3,3'-Divinyl-1,1'(1,6-hexanediyl) diimidazolium dibromide $\left(\mathrm{C}_{6} \mathrm{vim}_{2} \mathrm{Br}_{2}\right)$ was easily synthesized as we reported before. ${ }^{24}$ 1,6-Dibromohexane was purchased from J\&K, and 1-vinylimidazole was provided by TCI. $\mathrm{KReO}_{4}$ was obtained from Alfa Aesar. Re standard solution was provided by NCS Testing Technology Co., Ltd. Some $\mathrm{HNO}_{3}$ mother solutions with certain concentrations were prepared from GR $\mathrm{HNO}_{3}$ (Xilong Chemical Co., Ltd.) and titrated. Other chemicals were analytical-grade reagents. Deionized water was used throughout the experiments.

\subsection{Preparation and characterization of $\mathrm{PC}_{2}-\mathrm{C}_{12}$ vimBr gels}

Preparation of $\mathbf{P C}_{2}-\mathbf{C}_{12}$ vimBr gels. $\mathrm{C}_{2}$ vimBr, $\mathrm{C}_{12}$ vimBr and $\mathrm{C}_{6} \mathrm{vim}_{2} \mathrm{Br}_{2}$ were mixed into an aqueous solution and added into a glass test tube. It was then $\gamma$-irradiated at a dose rate of $c a .40$ Gy $\min ^{-1}$ to a dose of $40 \mathrm{kGy}$ by the ${ }^{60} \mathrm{Co}$ source, which was calibrated by Fricke dosimeter. The solution became into a white opaque gel after radiation. The concentration of $\mathrm{C}_{6} \mathrm{vim}_{2} \mathrm{Br}_{2}$ crosslinker was set as $0.05 \mathrm{M}$. The total concentration of $\mathrm{C}_{2}$ vimBr and $\mathrm{C}_{12}$ vimBr monomers was $1 \mathrm{M}$, and their feed ratios and the short names of the resulted gels were shown in Table 1.

The resulted gels were cut into round pieces with a thickness of $c a .3 \mathrm{~mm}$, and then every round piece was evenly cut into 4 sector pieces for further usage. The gels was immersed into excess ethanol for more than 6 times (at least 1 day for every time) to remove the sol part, and was subsequently put into excess water for more than 4 times. Then the gels were dried under $60{ }^{\circ} \mathrm{C}$ for more than 2 days to a constant weight. Gel fraction (GF) and equilibrium degree of swelling (EDS) were measured by gravimetry.

GF is defined as:

$$
\mathrm{GF}(\%)=w_{\mathrm{g}} / w_{0} \times 100
$$

where $w_{\mathrm{g}}$ is the weight of dry gel after removing the sol part, and $w_{0}$ is the initial weight of dry gel.

EDS is defined as:

$$
\operatorname{EDS}=w_{\mathrm{e}} / w_{\mathrm{d}}
$$

where $w_{\mathrm{d}}$ is the dry weight of the gel and $w_{\mathrm{e}}$ is the weight of the swelled gel after swelling equilibrium.

Characterization of $\mathbf{P C}_{2}-\mathbf{C}_{12}$ vimBr gels. IR spectra were obtained from Nicolet iS50. XPS was performed on Axis Ultra (Kratos Analytical) and B.E. were calibrated by $\mathrm{C}$ 1s hydrocarbon peak as $284.80 \mathrm{eV}$. Elemental Analysis (EA) was performed on Elementar Vario EL CUBE. SEM images were measured using Nova NanoSEM 430, and the samples were prepared by freezedrying from gels well swelled in water.

\subsection{Adsorption of $\mathrm{ReO}_{4}{ }^{-}$onto $\mathrm{PC}_{2}-\mathrm{C}_{12}$ vimBr gels}

The mother solution of Re was prepared from deionized water and $\mathrm{KReO}_{4}$. Inductively coupled plasma atomic emission spectroscopy (ICP-AES, Prodigy) was used to measure the Re concentration, and the relative error of Re concentration was estimated as $2 \%$.

Table 1 Feed concentrations of monomers and the resulted gels

\begin{tabular}{llll}
\multicolumn{2}{l}{ Feed concentrations $(\mathrm{M})$} & & $\begin{array}{l}\text { Names of the } \\
\text { resulted gels }\end{array}$ \\
\hline $\mathrm{C}_{2} \mathrm{vimBr}$ & $\mathrm{C}_{12} \mathrm{vimBr}$ & $\mathrm{C}_{6} \mathrm{vim}_{2} \mathrm{Br}_{2}$ & \\
0 & 1 & 0.05 & $\mathrm{PC}_{12} \mathrm{VimBr}$ \\
0.2 & 0.8 & 0.05 & $\mathrm{PC}_{2}-\mathrm{C}_{12} \mathrm{VimBr}-\mathrm{A}$ \\
0.4 & 0.6 & 0.05 & $\mathrm{PC}_{2}-\mathrm{C}_{12} \mathrm{vimBr}-\mathrm{B}$ \\
0.6 & 0.4 & 0.05 & $\mathrm{PC}_{2}-\mathrm{C}_{12} \mathrm{VimBr}-\mathrm{C}$ \\
0.8 & 0.2 & 0.05 & $\mathrm{PC}_{2}-\mathrm{C}_{12} \mathrm{VimBr}-\mathrm{D}$
\end{tabular}


Typically, an adsorption experiment was performed as following: a piece of gel was immersed into a Re solution, the mass ratio of the gel to the solution was $1 \mathrm{mg}$ gel per $1 \mathrm{~g}$ solution. The system was shaked in a shaker at $25{ }^{\circ} \mathrm{C}$ for $c a .2$ days to reach equilibrium, and the concentration of $\mathrm{Re}$ in the resulted solution was measured by ICP-AES.

The Re uptake, $q$, was calculated as following:

$$
q=\frac{\left(c_{0}-c\right) \times m_{\mathrm{s}}}{m_{\mathrm{g}}}
$$

where $c_{0}$ is the concentration of Re before adsorption, and $c$ is the concentration of Re after adsorption, while $m_{\mathrm{s}}$ is the mass of the solution, and $m_{\mathrm{g}}$ is the mass of the dry gel.

Adsorption kinetics. Since the gels were composed of imidazolium units with different molecular weights, sector pieces of gels with the similar sizes before washing were used to compare their adsorption kinetics. The gels were ca. 20-40 mg, and the corresponding $m_{\mathrm{s}}$ was constant at $50 \mathrm{~g}$. $100 \mu \mathrm{L}$ of solution was taken out from the system at a certain time and diluted to measure the Re concentration.

Adsorption isotherms and selectivity. For adsorption isotherms, a series of $q$ and $c$ were measured with varied $c_{0}$. For adsorption selectivity, $\mathrm{NO}_{3}{ }^{-}$and $\mathrm{Br}^{-}$, which were from $\mathrm{HNO}_{3}$ and $\mathrm{NaBr}$ respectively, were chosen as anion competitors.

In the competitive adsorption against $\mathrm{NO}_{3}{ }^{-}$, the anion of the gel were exchanged into $\mathrm{NO}_{3}{ }^{-}$before the adsorption, forming $\mathrm{PC}_{2}-\mathrm{C}_{12}$ vimNO $\mathrm{N}_{3}$-A. In detail, $\mathrm{PC}_{2}-\mathrm{C}_{12}$ vimBr-A was immersed into excess ca. $1.5 \mathrm{M} \mathrm{HNO}_{3}$ to equilibrium for 2 times, then into water for 3 times and dried. XPS and IR were performed to confirm the formation of $\mathrm{PC}_{2}-\mathrm{C}_{12}$ vimNO 3 -A (Fig. S1 $\dagger$ ).

The selective factor ( $\mathrm{SF}$ ) was used to evaluate the selectivities toward $\mathrm{ReO}_{4}{ }^{-}$against $\mathrm{NO}_{3}{ }^{-}$and $\mathrm{Br}^{-}$. SF was defined as: ${ }^{36}$

$$
\mathrm{SF}=\frac{q(\mathrm{Re}) \times c(\text { competitor })}{q(\text { competitor }) \times c(\mathrm{Re})}
$$

where $q$ is the uptake of the corresponding ion, and should be converted into the same unit $\left(\mathrm{mmol} \mathrm{g}^{-1}\right)$. And $c$ is the remained concentration (converted into mol kg${ }^{-1}$ ) of the corresponding ion at equilibrium. Thus, SF is a dimensionless number and suitable for the comparison between different adsorbents.

The $\mathrm{SF}$ of $\mathrm{PC}_{2} \mathrm{vimBr}$, a Re adsorbent reported in our previous work, ${ }^{24}$ towards $\mathrm{ReO}_{4}{ }^{-}$against $\mathrm{NO}_{3}{ }^{-}$was measured by the same procedure.

For the selective adsorption in ethanol-water mix solvent, the concentration of $\mathrm{HNO}_{3}$ was $0.05 \mathrm{~mol} \mathrm{~kg}^{-1}$.

Adsorption thermodynamics. In the solution, the $c_{0}$ was $700 \mathrm{ppm}$, and the concentration of $\mathrm{HNO}_{3}$ was $0.05 \mathrm{~mol} \mathrm{~kg}{ }^{-1}$. The phase ratio was $1 \mathrm{mg}$ gel per $1 \mathrm{~g}$ solution, and the solution was more than $60 \mathrm{~g}$ in each system. The system was shaken in a shaker for more than 2 days at each temperature, then $100 \mu \mathrm{L}$ of solution was taken to measure the $c$. Less than $1 \%$ of the solution was taken out for measurement during the whole experiment to avoid the influence by the change of the solution volume.

Adsorption cycles. In the first cycle, a piece of $\mathrm{PC}_{2}-\mathrm{C}_{12} \mathrm{vimBr}$ A was used to adsorb $\mathrm{ReO}_{4}{ }^{-}\left(c_{0}=1176 \mathrm{ppm}\right)$ and became $\mathrm{PC}_{2^{-}}$ $\mathrm{C}_{12}$ vimReO 4 -A after the adsorption. Then $\mathrm{PC}_{2}-\mathrm{C}_{12}$ vimReO $\mathrm{O}_{4}-\mathrm{A}$ was desorbed by $5.40 \mathrm{~mol} \mathrm{~kg}^{-1} \mathrm{HNO}_{3}\left(1 \mathrm{~g}\right.$ per $\mathrm{mg} \mathrm{PC}_{2}-\mathrm{C}_{12}$ VimBrA), and the solution was collected to measure the amount of desorbed Re. After that it was further immersed into $5.40 \mathrm{~mol}$ $\mathrm{kg}^{-1} \mathrm{HNO}_{3}$ for another time and then into water for 3 times to get rid of the residual $\mathrm{ReO}_{4}{ }^{-}$and $\mathrm{HNO}_{3}$. Thus $\mathrm{PC}_{2}-\mathrm{C}_{12}$ vimNO $3-\mathrm{A}$ was formed and used for the next cycle. After 4 cycles, IR and XPS were performed to the resulted $\mathrm{PC}_{2}-\mathrm{C}_{12} \mathrm{vimNO}_{3}-\mathrm{A}$ to confirm the desorption, as well as to the $\mathrm{PC}_{2}-\mathrm{C}_{12}$ vimReO 4 - $\mathrm{A}$ in the first cycle to confirm the adsorption.

\section{Result and discussion}

\subsection{Preparation and characterization of $\mathrm{PC}_{2}-\mathrm{C}_{12}$ vimBr gels}

Radiation-induced polymerization and crosslinking is a green and clean method widely used to prepare gels, ${ }^{37}$ and it has been proved to be effective for the preparation of poly ionic liquid gels in our previous works. ${ }^{24}$ The synthesis of $\mathrm{PC}_{2}-\mathrm{C}_{12}$ vimBr gels

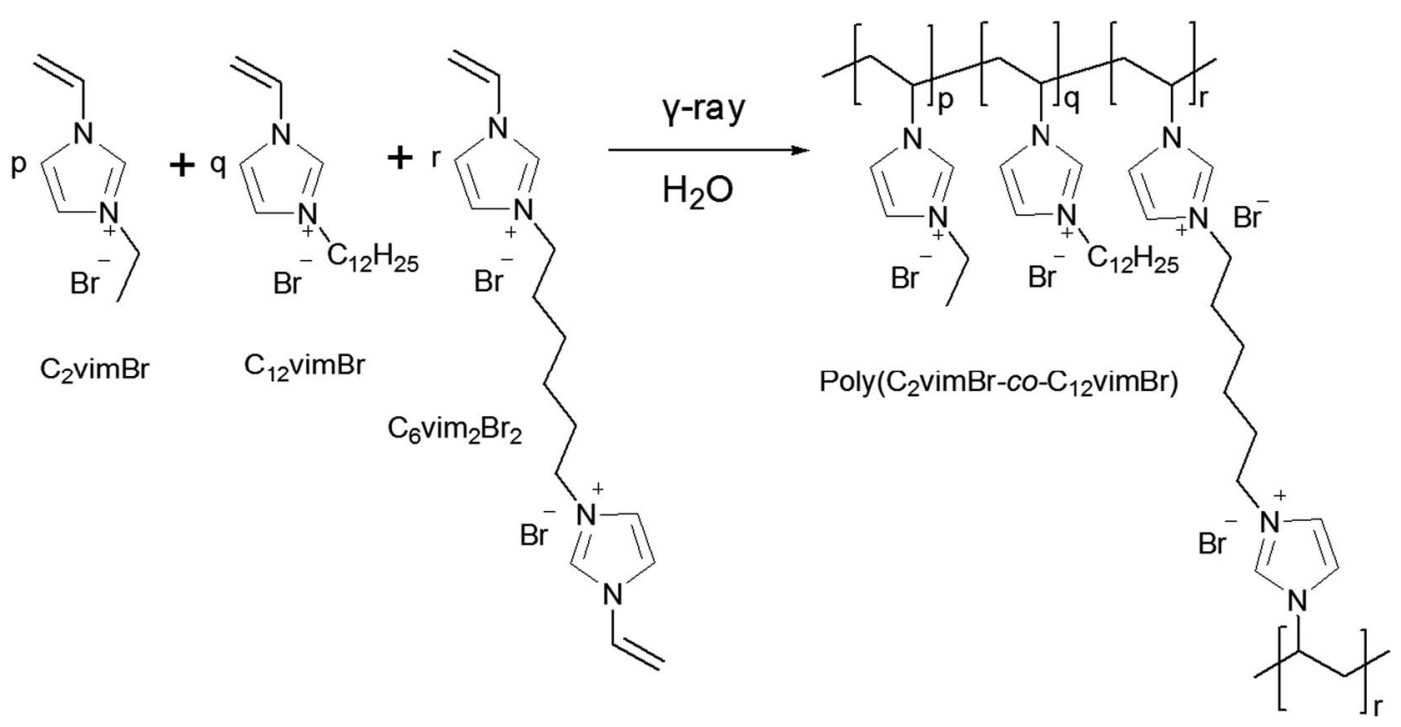

Scheme 1 


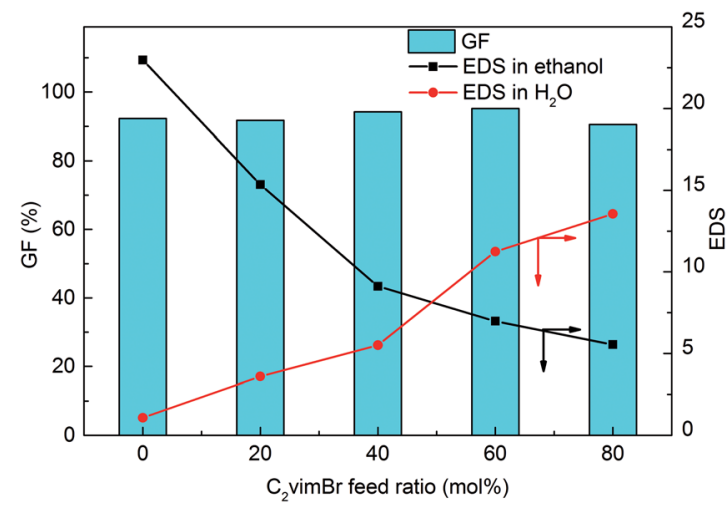

Fig. $1 \mathrm{GF}$ and $\mathrm{EDS}$ of the $\mathrm{PC}_{12} \mathrm{vimBr}$ gel and $\mathrm{PC}_{2}-\mathrm{C}_{12} \mathrm{vimBr}$ gels.

was illustrated in Scheme 1, and the GF and the EDS of $\mathrm{PC}_{2}$ $\mathrm{C}_{12}$ vimBr gels were shown in Fig. 1 .

The GFs of all $\mathrm{PC}_{2}-\mathrm{C}_{12} \mathrm{vimBr}$ gels with different compositions synthesized under $40 \mathrm{kGy}$ were above $90 \%$, which indicated that $\gamma$-radiation-induced polymerization and crosslinking was suitable and effective for this system. IR, TGA, EA, and XPS were performed to confirm the composition and structure of the resultant gels, and the results were shown in the ESI (Fig. S2-S4 and Table S1 $\dagger$ ).

$\mathrm{PC}_{12}$ vimBr, which had no $\mathrm{C}_{2}$ vimBr units, nearly did not swell in water, but it swelled well in ethanol. The EDS of $\mathrm{PC}_{2}-\mathrm{C}_{12} \mathrm{vimBr}$ gels in water increased with the increasing $\mathrm{C}_{2} \mathrm{vimBr}$ content, while the EDS in ethanol decreased. Since all the five gels had the same crosslinker content, the differences of the EDS of the gels in water and in ethanol were due to the different contents of the short-chain $\mathrm{C}_{2} \mathrm{vimBr}$ units and the long-chain $\mathrm{C}_{12} \mathrm{vimBr}$ units, and the results reflected the hydrophilicities and hydrophobicities of the gels. The more $\mathrm{C}_{2} \mathrm{vimBr}$ units the gel contains, the more hydrophilic it was, while the $\mathrm{C}_{12} \mathrm{vimBr}$ units contributed to the hydrophobicity of the gel.

SEM images were taken from the xerogels prepared by freezedrying of the corresponding gels swelled in water. SEM images of $\mathrm{PC}_{2}-\mathrm{C}_{12}$ vimBr-A, $\mathrm{PC}_{2}-\mathrm{C}_{12}$ vimBr-D and $\mathrm{PC}_{12}$ vimBr gel were shown in Fig. 2. Among the three samples, $\mathrm{PC}_{2}-\mathrm{C}_{12} \mathrm{vimBr}-\mathrm{D}$ had the largest holes, and it was agreed with its highest EDS in water. $\mathrm{PC}_{2}-\mathrm{C}_{12}$ vimBr-A, which had least $\mathrm{C}_{2}$ vimBr units among $\mathrm{PC}_{2}-\mathrm{C}_{12}$ vimBr gels, also had small holes, while it could swell a little in water. In the image of $\mathrm{PC}_{12} \mathrm{vimBr}$, the section was rough and no hole could be observed. $\mathrm{PC}_{12} \mathrm{vimBr}$ was relatively hydrophobic, and did not swell in water, while even a small amount of $\mathrm{C}_{2} \mathrm{vimBr}$ units could give the gels hydrophilicity and make them swell in water, which would improve their adsorption kinetics.

\subsection{The adsorption kinetics of $\mathrm{ReO}_{4}^{-}$onto $\mathrm{PC}_{2}-\mathrm{C}_{12} \mathrm{vimBr}$ gels}

$\mathrm{PC}_{2}-\mathrm{C}_{12} \mathrm{VimBr}$ gel had a cationic polymer network with $\mathrm{Br}^{-}$as exchangeable counteranion, so anions such as $\mathrm{ReO}_{4}{ }^{-}$can be attracted easily by $\mathrm{PC}_{2}-\mathrm{C}_{12} \mathrm{vimBr}$ gel and then be adsorbed by anion-exchange. The adsorption kinetics of $\mathrm{ReO}_{4}{ }^{-}$onto four $\mathrm{PC}_{2}-\mathrm{C}_{12} \mathrm{vimBr}$ gels were shown in Fig. 3a, and that of $\mathrm{PC}_{12} \mathrm{vimBr}$ was shown in Fig. $3 \mathrm{~b}$.

For all the four $\mathrm{PC}_{2}-\mathrm{C}_{12}$ vimBr gels, the kinetics had no significant difference. The adsorption equilibriums were achieved at $c a .24 \mathrm{~h}$, which was similar to the equilibrium time of poly(4-vinylpyridine) resins. ${ }^{29}$ However, $\mathrm{PC}_{12} \mathrm{vimBr}$ shown a quite slow adsorption kinetics, and could not achieve equilibrium in even 3 months. This was due to the high hydrophobicity of $\mathrm{PC}_{12} \mathrm{vimBr}$, and as shown in Fig. $2 \mathrm{c}$, it had no porous structure in water. On the other hand, as little as $20 \mathrm{~mol} \%$ of the short-chain $\mathrm{C}_{2} \mathrm{vimBr}$ units could improve the hydrophilicity of the gel, and further efficiently improve the adsorption kinetics. Upon $20 \mathrm{~mol} \%$, more $\mathrm{C}_{2} \mathrm{vimBr}$ units did not show significant improvement to the adsorption kinetics. Since we introduced the long-chain $\mathrm{C}_{12} \mathrm{vimBr}$ units aiming at improving the adsorption selectivity towards $\mathrm{ReO}_{4}{ }^{-}$(the gels with lower $\mathrm{C}_{12} \mathrm{vimBr}$ contents had lower adsorption selectivity towards $\mathrm{ReO}_{4}{ }^{-}$, see Fig. $\left.\mathrm{S}_{\dagger} \dagger\right), \mathrm{PC}_{2}-\mathrm{C}_{12}$ vimBr-A, which had the highest content of $\mathrm{C}_{12} \mathrm{vimBr}$ units among the gels with suitable kinetics, was chosen for the further adsorption experiments.

\subsection{The adsorption isotherms and selectivity of $\mathbf{P C}_{2^{-}}$ $\mathrm{C}_{12}$ vimBr-A towards $\mathrm{ReO}_{4}$}

The adsorption isotherms. The adsorption isotherms of $\mathrm{ReO}_{4}{ }^{-}$onto $\mathrm{PC}_{2}-\mathrm{C}_{12}$ vimBr-A was shown in Fig. 4.

The adsorption isotherms of $\mathrm{ReO}_{4}{ }^{-}$onto $\mathrm{PC}_{2}-\mathrm{C}_{12}$ vimBr-A agreed with the Langmuir model well:

$$
q=q_{\mathrm{m}} \times \frac{k c}{1+k c}
$$

where $q_{\mathrm{m}}$ is the adsorption capacity, and $k$ is the Langmuir constant.

And it was fitted in the linear form:

$$
\frac{c}{q}=\frac{c}{q_{\mathrm{m}}}+\frac{1}{q_{\mathrm{m}} k}
$$

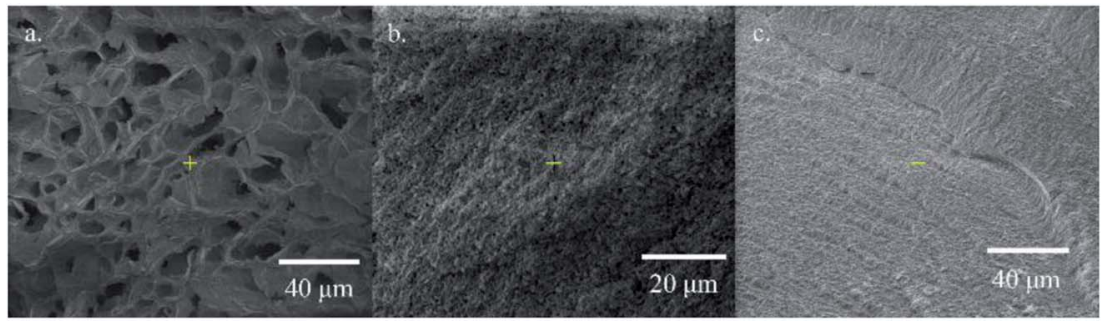

Fig. 2 SEM images of (a) $P C_{2}-C_{12} v i m B r-D$, (b) $P C_{2}-C_{12} v i m B r-A$, and (c) $P C_{12} v i m B r$. 

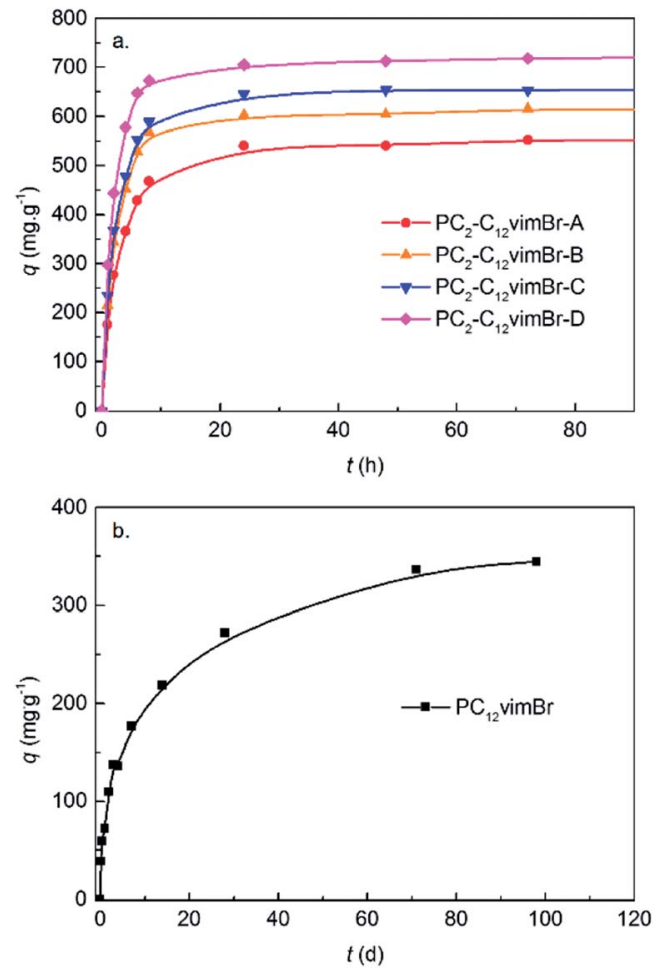

Fig. 3 Adsorption kinetics of $\mathrm{ReO}_{4}{ }^{-}$onto (a) $\mathrm{PC}_{2}-\mathrm{C}_{12} \mathrm{vimBr}$ gels and (b) $\mathrm{PC}_{12} \mathrm{vimBr}$. The $c_{0}$ was $557 \mathrm{ppm}$.

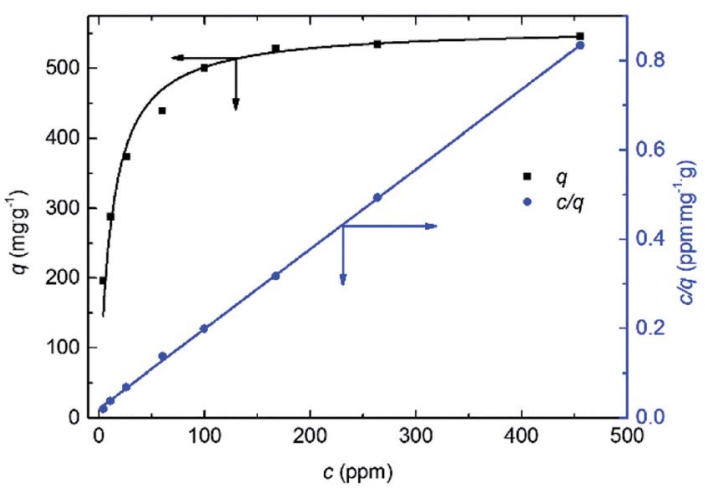

Fig. 4 Adsorption isotherms of $\mathrm{ReO}_{4}{ }^{-}$onto $\mathrm{PC}_{2}-\mathrm{C}_{12} \mathrm{vimBr}-\mathrm{A}$.

The parameters of fitting and the calculated $q_{\mathrm{m}}$ and $k$ were shown in Table 2:

The $q_{\mathrm{m}}$ of Re onto $\mathrm{PC}_{2}-\mathrm{C}_{12}$ vimBr-A was $559 \mathrm{mg}$ Re per $\mathrm{g}$ gel, which was equal to the theoretical value calculated from the $N$ wt\% in the EA of $\mathrm{PC}_{2}-\mathrm{C}_{12}$ vimBr-A, assuming every imidazolium group could adsorb one $\mathrm{ReO}_{4}{ }^{-}$ion:

$$
\begin{aligned}
q_{\mathrm{th}} & =\frac{\mathrm{wt}^{\%} \%(N)}{M_{\mathrm{w}}(N)} \times \frac{n(\text { imidazolium })}{n(N)} \times M_{\mathrm{w}}(\mathrm{Re}) \\
& =\frac{8.40 \%}{14.0} \times \frac{1}{2} \times 186.2 \mathrm{~g} \mathrm{~g}^{-1} \\
& =559 \mathrm{mg} \mathrm{g}^{-1}
\end{aligned}
$$

This result also supported that all imidazolium groups in $\mathrm{PC}_{2}-\mathrm{C}_{12}$ vimBr-A were utilized with a ratio to $\mathrm{ReO}_{4}{ }^{-}$of $1: 1$.

Since the long-chain unit $\mathrm{C}_{12}$ vimBr has larger $M_{\mathrm{w}}$ than that of $\mathrm{C}_{2}$ vimBr, the $q_{\mathrm{m}}$ of $\mathrm{PC}_{2}-\mathrm{C}_{12}$ vimBr-A was lower than that of the Re adsorbent $\mathrm{PC}_{2}$ vimBr we reported before, which was $865 \mathrm{mg}$ $\mathrm{g}^{-1} \cdot{ }^{24}$ However, as a gel adsorbent, $\mathrm{PC}_{2}-\mathrm{C}_{12}$ vimBr-A was fully composed of functional groups without matrix, its adsorption capacity was higher than most of the $\mathrm{Re}$ adsorbents reported. , 10,16 $^{3,0}$

For the practical usage of Re/Tc adsorbents, the selectivity is more important than the adsorption capacities. Because in practical systems, $\mathrm{TcO}_{4}{ }^{-}$usually presences with competitors, e.g. $\mathrm{HNO}_{3}$ in the PUREX. ${ }^{4}$ The results of the competitive adsorption against $\mathrm{Br}^{-}$and $\mathrm{NO}_{3}{ }^{-}$were shown in Fig. 5 .

As shown in Fig. 5, the $q$ of Re decreased with the increasing concentration of the competitor in all the three curves, and it was due to the competition of $\mathrm{NO}_{3}{ }^{-}$or $\mathrm{Br}^{-}$. SF should be a constant according to the Langmuir model, and was fluctuating around the average value among the investigated conditions. The average values of SF were listed in Table 3.

Comparing to $\mathrm{PC}_{2}$ vimNO 3 , the adsorbent we previously reported, ${ }^{24} \mathrm{PC}_{2}-\mathrm{C}_{12}$ vim $\mathrm{NO}_{3}-\mathrm{A}$ had an $\mathrm{SF}$ against $\mathrm{NO}_{3}{ }^{-}$more than 10 times higher than that of the former one, which illustrated its excellent selectivity towards $\mathrm{ReO}_{4}{ }^{-}$. Since few literatures about $\mathrm{Re}$ adsorbents have reported the SF between $\mathrm{NO}_{3}{ }^{-}$and $\mathrm{ReO}_{4}{ }^{-}$, it is a little difficult to compare the selectivities widely among these adsorbents, considering some reported quantities, e.g. distribution coefficient $K_{\mathrm{d}}$ or removal rate, are not only decided by the nature of the materials, but also by the experiment parameters such as the phase ratio of adsorbent/solution and the $c_{0}$ of Re. We estimated the SF towards $\mathrm{ReO}_{4}{ }^{-}$against $\mathrm{NO}_{3}{ }^{-}$of SCU-100, which is an excellent Re/Tc adsorbent reported recently with the highest $K_{\mathrm{d}}$ among inorganic Re adsorbents, from its adsorption capacity as $541 \mathrm{mg} \mathrm{ReO}_{4}{ }^{-}$per $\mathrm{g}$ SCU-100 and removal rate as $73 \%$ at $0.15 \mathrm{mM} \mathrm{ReO}_{4}{ }^{-}$and $15 \mathrm{mM}$ $\mathrm{NO}_{3}{ }^{-}$with a phase ratio of $1 \mathrm{~mL}$ solution per $1 \mathrm{mg}$ SCU-100: ${ }^{13}$

$$
\begin{aligned}
& \mathrm{SF}=\frac{q(\mathrm{Re}) \times c(\text { competitor })}{q(\text { competitor }) \times c(\mathrm{Re})} \\
& =\frac{(73 \% \times 0.15 \times 1 / 1) \mathrm{mmol} \mathrm{g}^{-1} \times 15 \mathrm{mM}}{(541 / 250.2-73 \% \times 0.15 \times 1 / 1) \mathrm{mmol} \mathrm{g}^{-1} \times(27 \% \times 0.15) \mathrm{mM}} \\
& =20
\end{aligned}
$$

It was illustrated that the measured $\mathrm{SF}$ of $\mathrm{PC}_{2}-\mathrm{C}_{12} \mathrm{vimNO}_{3}-\mathrm{A}$ was higher than the estimated $\mathrm{SF}$ of $\mathrm{SCU}-100$, i.e. $\mathrm{PC}_{2}$ $\mathrm{C}_{12}$ vimNO ${ }_{3}$-A had better selectivity towards $\mathrm{ReO}_{4}{ }^{-} \cdot \mathrm{PC}_{2}{ }^{-}$ $\mathrm{C}_{12}$ vimNO $_{3}$-A could remain $c a .100 \mathrm{mg} \mathrm{g}^{-1}$ Re uptake under $0.5 \mathrm{~mol} \mathrm{~kg}^{-1} \mathrm{HNO}_{3}$. It was even higher than the maximum

Table 2 Parameters of the adsorption of $\mathrm{ReO}_{4}{ }^{-}$onto $\mathrm{PC}_{2}-\mathrm{C}_{12} \mathrm{vimBr}-\mathrm{A}$ from the Langmuir model

\begin{tabular}{lllll}
$\begin{array}{l}\text { Intercept, } \\
1 / q_{\mathrm{m}} k\end{array}$ & Slope, $1 / q_{\mathrm{m}}$ & $R^{2}$ & $q_{\mathrm{m}},\left(\mathrm{mg} \mathrm{g}^{-1}\right)$ & $K,\left(\mathrm{ppm}^{-1}\right)$ \\
\hline 0.02036 & 0.00179 & 0.9997 & 559 & 0.0879
\end{tabular}



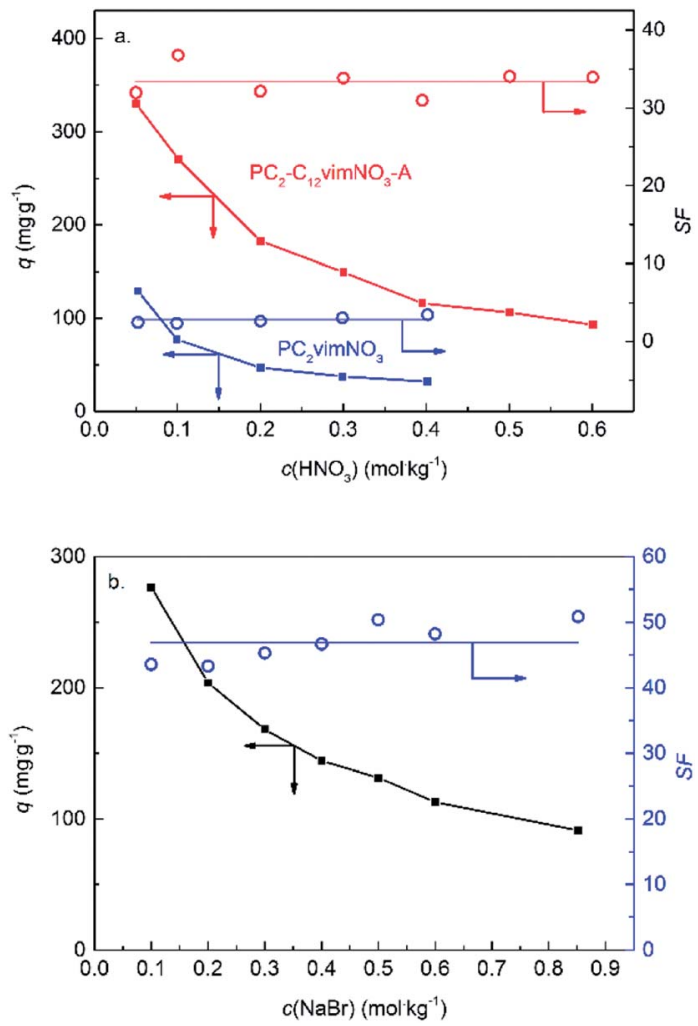

Fig. 5 (a) The competitive adsorption towards $\mathrm{ReO}_{4}{ }^{-}$against $\mathrm{NO}_{3}{ }^{-}$on $\mathrm{PC}_{2}-\mathrm{C}_{12}$ vimNO $\mathrm{N}_{3}-\mathrm{A}$ as well as on $\mathrm{PC}_{2} \mathrm{vimNO}$. (b) The competitive adsorption towards $\mathrm{ReO}_{4}{ }^{-}$against $\mathrm{Br}^{-}$on $\mathrm{PC}_{2}-\mathrm{C}_{12} \mathrm{vimBr}-\mathrm{A}$. The $\mathrm{C}_{0}$ was 700 ppm.

Table 3 The average values of the SF of $\mathrm{PC}_{2}-\mathrm{C}_{12}$ vimNO $3-\mathrm{A}, \mathrm{PC}_{2}$ vimNO 3 and $\mathrm{PC}_{2}-\mathrm{C}_{12}$ vimBr-A towards $\mathrm{ReO}_{4}{ }^{-}$against the corresponding competitors

\begin{tabular}{llr}
\hline Adsorbent & Competitor & \multicolumn{1}{c}{$\mathrm{SF}$} \\
\hline $\mathrm{PC}_{2}-\mathrm{C}_{12} \mathrm{VimNO}_{3}$-A & $\mathrm{NO}_{3}{ }^{-}$ & $33.4 \pm 1.9$ \\
$\mathrm{PC}_{2} \mathrm{VimNO}_{3}$ & $\mathrm{NO}_{3}{ }^{-}$ & $2.8 \pm 0.5$ \\
$\mathrm{PC}_{2}-\mathrm{C}_{12} \mathrm{VimBr}-\mathrm{A}$ & $\mathrm{Br}^{-}$ & $46.9 \pm 3.1$
\end{tabular}

adsorption capacities of some other reported adsorbents. ${ }^{3,38}$ The potential practical usage of $\mathrm{PC}_{2}-\mathrm{C}_{12}$ vimBr-A for the treatment of radioactive liquid wastes was revealed by such high $\mathrm{Re}$ uptake under this condition. The $\mathrm{SF}$ of $\mathrm{PC}_{2} \mathrm{vimBr}$ against $\mathrm{Br}^{-}$ was higher than that against $\mathrm{NO}_{3}{ }^{-}$, and it is agreed with the sequence of increasing hydration energies $\left(\mathrm{ReO}_{4}{ }^{-}<\mathrm{NO}_{3}{ }^{-}<\right.$ $\left.\mathrm{Br}^{-}\right) .{ }^{39}$

Varied contents of polar organic solvents in the mixed solvent could be used to investigate the effect of solvent on the adsorption. ${ }^{40}$ And the lower hydration energy of $\mathrm{ReO}_{4}{ }^{-}$than those of the competitors was widely used for the selective adsorption or extraction of $\mathrm{ReO}_{4}{ }^{-} \cdot{ }^{\mathbf{1}}$ Herein, ethanol was added in the solvent for illustrating the importance of water in the selective adsorption of $\mathrm{ReO}_{4}{ }^{-}$. As shown in Fig. 6, the $q$ as well as the SF were decreased with the increasing ethanol content. With increasing ethanol content, the activity of water decreased, thus the contribution of the differences of hydration energies to the selective adsorption was decreased for the system. So it could be concluded that water as a solvent played an important role in the selective adsorption of $\mathrm{ReO}_{4}{ }^{-}$onto $\mathrm{PC}_{2}-\mathrm{C}_{12}$ vimNO${ }_{3}-\mathrm{A}$ gel.

\subsection{The adsorption thermodynamics of $\mathrm{PC}_{2}-\mathrm{C}_{12}$ vimBr-A towards $\mathrm{ReO}_{4}$}

The SF of $\mathrm{PC}_{2}-\mathrm{C}_{12}$ vimNO${ }_{3}$-A towards $\mathrm{ReO}_{4}{ }^{-}$against $\mathrm{NO}_{3}{ }^{-}$can be considered as the $K$ of the following equation:

$$
\mathrm{PC}_{2}-\mathrm{C}_{12} \mathrm{vimNO}_{3}-\mathrm{A}+\mathrm{ReO}_{4}{ }^{-}=\mathrm{PC}_{2}-\mathrm{C}_{12} \mathrm{vimReO}_{4}-\mathrm{A}+\mathrm{NO}_{3}
$$

The $K$ under different temperatures were measured, and the relation between $\ln K$ and 1000/T (Fig. 7) were fitted by the van't Hoff equation:

$$
\ln K=-\frac{\Delta H^{\Theta}}{R T}+\frac{\Delta S^{\Theta}}{R}
$$

The $\Delta H^{\Theta}$ and $\Delta S^{\Theta}$ of eqn (9) were calculated from the slope and the intercept, which were $-16.9 \mathrm{~kJ} \mathrm{~mol}^{-1}$ and $29 \mathrm{~J} \mathrm{~mol}^{-1}$ $\mathrm{K}^{-1}$, respectively.

The negative $\Delta H^{\Theta}$ indicated that the adsorption process was exothermic, and lower temperature was beneficial to the adsorption process. The type of adsorption can be indicated by the magnitude of the enthalpy change value. Lower enthalpy change corresponds to physical adsorption, and higher one corresponds to chemical adsorption. The range of enthalpy change of physical adsorption is considered as $0-20 \mathrm{~kJ} \mathrm{~mol}^{-1}$ (ref. 41) or $0.5-5 \mathrm{kcal} \mathrm{mol}^{-1}\left(2.1-20.9 \mathrm{~kJ} \mathrm{~mol}^{-1}\right){ }^{42}$ The absolute value of $\Delta H^{\Theta}$ of eqn (9) was in the range of enthalpy change of physical adsorption, so the adsorption process of $\mathrm{PC}_{2}$ $\mathrm{C}_{12}$ vimNO ${ }_{3}$-A towards $\mathrm{ReO}_{4}{ }^{-}$was physical adsorption. This was agreed with the ion-exchange mechanism, where no covalent bond forms or breaks.

\subsection{The adsorption cycles and the adsorption mechanism of $\mathrm{PC}_{2}-\mathrm{C}_{12}$ vimBr-A towards $\mathrm{ReO}_{4}$}

Though $\mathrm{PC}_{2}-\mathrm{C}_{12}$ vimBr-A had high adsorption selectivity towards $\mathrm{ReO}_{4}{ }^{-}, \mathrm{ReO}_{4}{ }^{-}$can be exchanged into solution by high

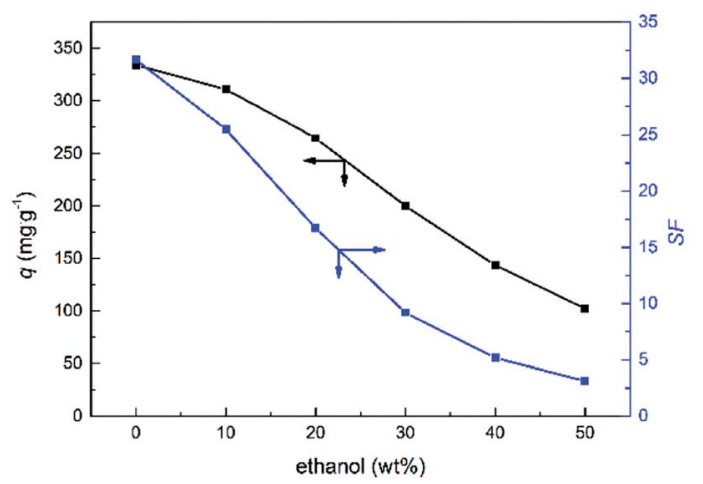

Fig. 6 The competitive adsorption towards $\mathrm{ReO}_{4}{ }^{-}$against $\mathrm{NO}_{3}{ }^{-}$on $\mathrm{PC}_{2}-\mathrm{C}_{12} \mathrm{VimNO}_{3}-\mathrm{A}$ in ethanol-water mix solvent. The $\mathrm{C}_{0}$ was $700 \mathrm{ppm}$. 


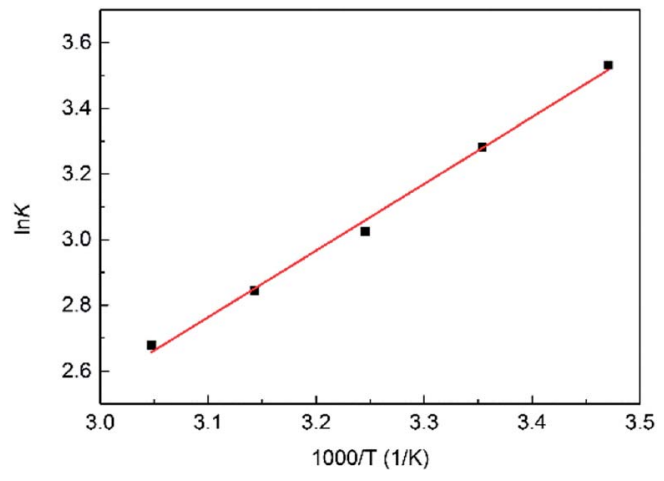

Fig. 7 Fitted curve of $\ln K-1000 / T$ of eqn (9).

concentration $\mathrm{NO}_{3}{ }^{-}$. So the used adsorbent can be renewed by $\mathrm{HNO}_{3}$ with high concentration resulting in the formation of $\mathrm{PC}_{2}-\mathrm{C}_{12}$ vimNO 3 -A. After washing off $\mathrm{HNO}_{3}$ by deionized water, $\mathrm{PC}_{2}-\mathrm{C}_{12} \mathrm{VimNO}_{3}-\mathrm{A}$ can adsorb $\mathrm{ReO}_{4}^{-}$again by anionexchanging. The adsorption cycles of $\mathrm{PC}_{2}-\mathrm{C}_{12} \mathrm{vimBr}-\mathrm{A}$ towards $\mathrm{ReO}_{4}{ }^{-}$were shown in Fig. 8, where the Re uptake were marked by red and the Re desorbed in the first wash by $5.40 \mathrm{~mol} \mathrm{~kg}^{-1}$ $\mathrm{HNO}_{3}$ were marked by blue.

The $q$ in the second cycle was reduced to $c a .96 \%$ of that of the first cycle and kept well in the next two cycles. The decrease of $q$ after the first cycle could be explained by the anion exchange from $\mathrm{Br}^{-}$to $\mathrm{NO}_{3}{ }^{-}$after the first cycle. $\mathrm{PC}_{2}-\mathrm{C}_{12}{ }^{-}$ vimReO ${ }_{4}$ - $\mathrm{A}$ could be renewed into $\mathrm{PC}_{2}-\mathrm{C}_{12} \mathrm{vimNO}_{3}-\mathrm{A}$ by $\mathrm{HNO}_{3}$ and the adsorbent had excellent reusability. ${\mathrm{Most} \mathrm{ReO}_{4}}^{-}$could be desorbed in the first wash by $5.4 \mathrm{~mol} \mathrm{~kg}^{-1} \mathrm{NO}_{3}{ }^{-}$, and the second wash could renew almost all the ion-exchange positions. The eluted Re in $\mathrm{HNO}_{3}$ solution exists without any other salts, and can be made into Re products for other usages easily, or disposed separately from other wastes.

IR and XPS were performed to characterize $\mathrm{PC}_{2}-\mathrm{C}_{12}$ vimBr-A,

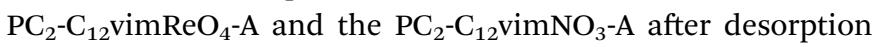
(Fig. 9).

As $\mathrm{Br}^{-}$has no IR absorbance, the peaks of the polymeric imidazolium cation were revealed clearly in the IR spectrum of $\mathrm{PC}_{2}-\mathrm{C}_{12}$ vimBr-A. After the adsorption of $\mathrm{ReO}_{4}{ }^{-}$, in the IR spectrum of $\mathrm{PC}_{2}-\mathrm{C}_{12}$ vimReO${ }_{4}-\mathrm{A}$, no change of the peaks of the polymeric imidazolium cation could be observed, and the peak

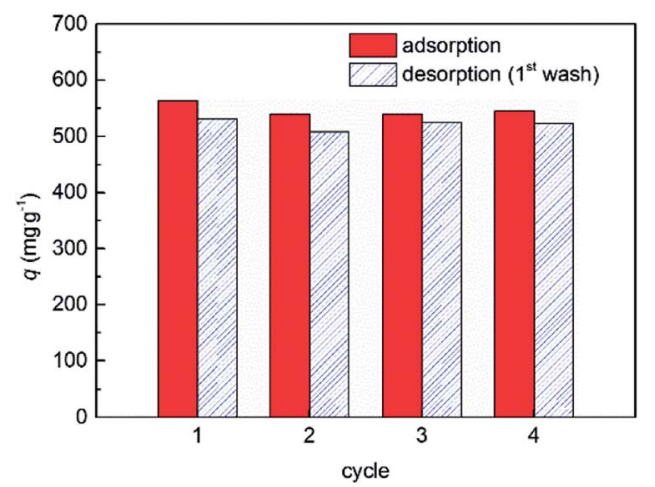

Fig. 8 The adsorption cycles of $\mathrm{ReO}_{4}{ }^{-}$on $\mathrm{PC}_{2}-\mathrm{C}_{12} \mathrm{VimBr}-\mathrm{A}$.
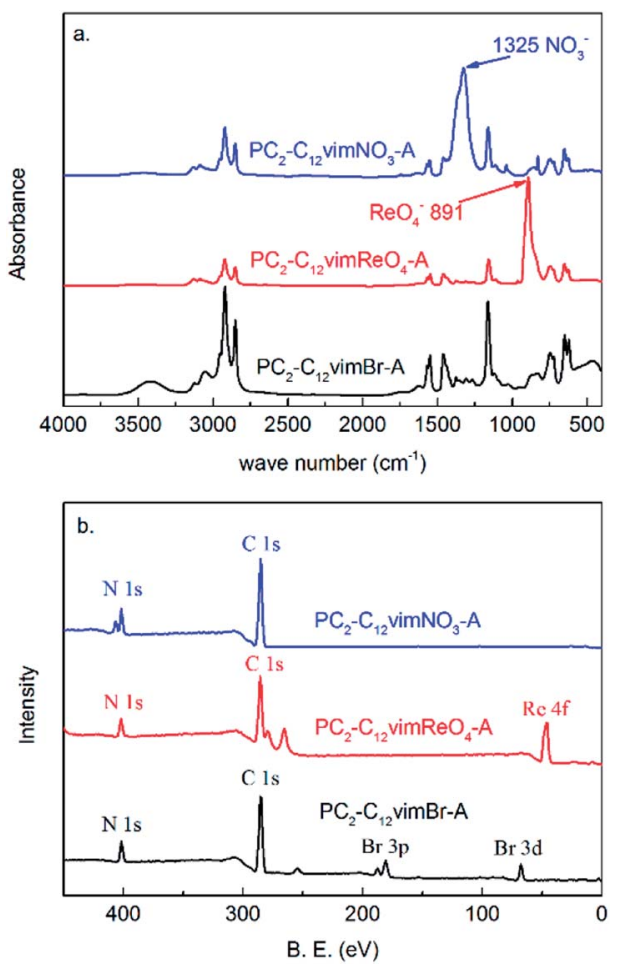

Fig. 9 The (a) IR and (b) XPS pattern of $\mathrm{PC}_{2}-\mathrm{C}_{12} \mathrm{vimBr}-\mathrm{A}, \mathrm{PC}_{2}-\mathrm{C}_{12^{-}}$ vimReO${ }_{4}-\mathrm{A}$ and the $\mathrm{PC}_{2}-\mathrm{C}_{12} \mathrm{VimNO}_{3}-\mathrm{A}$ after desorption.

of $\mathrm{ReO}_{4}{ }^{-}$at $891 \mathrm{~cm}^{-1}$ occurred. After the desorption by $5.4 \mathrm{~mol}$ $\mathrm{kg}^{-1} \mathrm{HNO}_{3}$, the peak of $\mathrm{ReO}_{4}{ }^{-}$disappeared, and the strong peak of $\mathrm{NO}_{3}{ }^{-}$at $1325 \mathrm{~cm}^{-1}$ occurred, while the other peaks showed no change. It could be concluded from the IR spectra that the polymeric imidazolium cation did not change during the adsorption and the desorption process, and $\mathrm{ReO}_{4}{ }^{-}$and $\mathrm{NO}_{3}{ }^{-}$ were exchanged onto the polycation without valence change. The XPS also confirmed the adsorption and the desorption was successful. The peak of Re occurred in $\mathrm{PC}_{2}-\mathrm{C}_{12}$ vimReO${ }_{4}-\mathrm{A}$ instead of that of $\mathrm{Br}$ in $\mathrm{PC}_{2}-\mathrm{C}_{12} \mathrm{vimBr}-\mathrm{A}$, and it disappeared in the XPS of $\mathrm{PC}_{2}-\mathrm{C}_{12} \mathrm{vimNO}_{3}-\mathrm{A}$ after desorption. The peak of $\mathrm{N}$ in $\mathrm{PC}_{2}-\mathrm{C}_{12} \mathrm{VimNO}_{3}-\mathrm{A}$ was a double peak, instead of the single peaks in $\mathrm{PC}_{2}-\mathrm{C}_{12}$ vimBr-A and $\mathrm{PC}_{2}-\mathrm{C}_{12}$ vimReO ${ }_{4}-\mathrm{A}$, for the $\mathrm{N}$ in $\mathrm{PC}_{2}-$ $\mathrm{C}_{12} \mathrm{vimNO}_{3}$-A could be divided into two kinds with different B.E., which belonged to $\mathrm{NO}_{3}{ }^{-}$and imidazolium respectively (see also Fig. S1 $\dagger$ ). So an ion-exchange mechanism could be concluded from the IR and the XPS results.

Furthermore, as an anion-exchange gel, $\mathrm{PC}_{2}-\mathrm{C}_{12} \mathrm{vimBr}$ may be used for the adsorption of other anions, such as $\mathrm{Cr}(\mathrm{vI})$ anions, anionic surfactants and anionic dyes in the future.

\section{Conclusions}

Polymeric ionic liquid gels, $\mathrm{PC}_{2}-\mathrm{C}_{12} \mathrm{vimBr}$, was synthesized by radiation-induced polymerization and crosslinking, and its adsorption behavior towards $\mathrm{ReO}_{4}{ }^{-}$was investigated. The $\mathrm{PC}_{2}{ }^{-}$ $\mathrm{C}_{12}$ vimBr gel contained two kinds of imidazolium units, namely the hydrophilic units composed of ethylimidazolium and the hydrophobic units composed of dodecylimidazolium. Addition of small amount of hydrophilic units could effectively improve 
the adsorption kinetics of $\mathrm{PC}_{12} \mathrm{vimBr}$ gel, and the addition of hydrophobic units could improve the adsorption selectivity towards $\mathrm{ReO}_{4}{ }^{-}$of $\mathrm{PC}_{2}$ vimBr gel. $\mathrm{PC}_{2}-\mathrm{C}_{12}$ vimBr-A gel, with $20 \mathrm{~mol} \%$ hydrophilic units and $80 \mathrm{~mol} \%$ hydrophobic units, had an adsorption equilibrium time of $c a .24 \mathrm{~h}$ and adsorption capacity as high as $559 \mathrm{mg} \mathrm{g}^{-1}$ (mg Re per g gel). Its SF towards $\mathrm{ReO}_{4}{ }^{-}$against $\mathrm{NO}_{3}{ }^{-}$was $33.4 \pm 1.9$, which was more than 10 times of that of $\mathrm{PC}_{2} \mathrm{vimBr}$, and it could keep a Re uptake as high as $100 \mathrm{mg} \mathrm{g}^{-1}$ in $0.5 \mathrm{~mol} \mathrm{~kg} \mathrm{kNO}_{3}$, which revealed its potential application in the treatment of $\mathrm{Tc}$ in radioactive liquid wastes. The adsorption mechanism was ion-exchange, and the selective adsorption was driven by the low hydration energy of $\mathrm{ReO}_{4}{ }^{-}$and the hydrophobicity of the polycation. The $\Delta H^{\Theta}$ and $\Delta S^{\Theta}$ of the $\mathrm{NO}_{3}{ }^{-} / \mathrm{ReO}_{4}{ }^{-}$ion-exchange reaction of $\mathrm{PC}_{2}-\mathrm{C}_{12} \mathrm{VimNO}_{3}{ }^{-}$ A were $-16.9 \mathrm{KJ} \mathrm{mol}^{-1}$ and $29 \mathrm{~J} \mathrm{~mol}^{-1} \mathrm{~K}^{-1}$, respectively. The adsorbent could be renewed by $5.4 \mathrm{~mol} \mathrm{~kg}{ }^{-1} \mathrm{HNO}_{3}$ for several times with high adsorption performance maintenance. The work provided a new approach to prepare novel ionic gel adsorbent by controlling the hydrophilicity and hydrophobicity of adsorbents which are related to the kinetics and selectivity towards adsorbates, respectively.

\section{Conflicts of interest}

There are no conflicts to declare.

\section{Acknowledgements}

The National Natural Science Foundation of China (NNSFC, Project No. 21471161 and 11375019) and the Scientific and Technological Plan of Shenzhen City (JCYJ 20150616163111759) are acknowledged for supporting this research.

\section{Notes and references}

1 D. Banerjee, D. Kim, M. J. Schweiger, A. A. Kruger and P. K. Thallapally, Chem. Soc. Rev., 2016, 45, 2724-2739.

2 S. Sarri, P. Misaelides, D. Zamboulis, X. Gaona, M. Altmaier and H. Geckeis, J. Radioanal. Nucl. Chem., 2016, 307, 681689.

3 X. Shu, L. Shen, Y. Wei and D. Hua, J. Mol. Liq., 2015, 211, 621-627.

4 I. Yamagishi and M. Kubota, J. Nucl. Sci. Technol., 1993, 30, 717-719.

5 B. A. Lenell and Y. Arai, J. Hazard. Mater., 2017, 321, 335-343. 6 T. L. Yu, S. Q. Liu, M. Xu, J. Peng, J. Q. Li and M. L. Zhai, Radiat. Phys. Chem., 2016, 125, 94-101.

7 J. J. Neeway, R. M. Asmussen, A. R. Lawter, M. E. Bowden, W. W. Lukens, D. Sarma, B. J. Riley, M. G. Kanatzidis and N. P. Qafoku, Chem. Mater., 2016, 28, 3976-3983.

8 C. D. Williams and P. Carbone, Environ. Sci. Technol., 2016, 50, 3875-3881.

9 S. A. Wang, E. V. Alekseev, D. W. Juan, W. H. Casey, B. L. Phillips, W. Depmeier and T. E. Albrecht-Schmitt, Angew. Chem., Int. Ed., 2010, 49, 1057-1060.

10 S. A. Wang, P. Yu, B. A. Purse, M. J. Orta, J. Diwu, W. H. Casey, B. L. Phillips, E. V. Alekseev, W. Depmeier,
D. T. Hobbs and T. E. Albrecht-Schmitt, Adv. Funct. Mater., 2012, 22, 2241-2250.

11 D. Banerjee, S. K. Elsaidi, B. Aguila, B. Li, D. Kim, M. J. Schweiger, A. A. Kruger, C. J. Doonan, S. Ma and P. K. Thallapally, Chem.-Eur. J., 2016, 22, 17581-17584.

12 D. Banerjee, W. Xu, Z. Nie, L. E. V. Johnson, C. Coghlan, M. L. Sushko, D. Kim, M. J. Schweiger, A. A. Kruger, C. J. Doonan and P. K. Thallapally, Inorg. Chem., 2016, 55, 8241-8243.

13 D. Sheng, L. Zhu, C. Xu, C. Xiao, Y. Wang, Y. Wang, L. Chen, J. Diwu, J. Chen, Z. Chai, T. E. Albrecht-Schmitt and S. Wang, Environ. Sci. Technol., 2017, 51, 3471-3479.

14 A. V. Desai, B. Manna, A. Karmakar, A. Sahu and S. K. Ghosh, Angew. Chem., Int. Ed., 2016, 55, 7811-7815.

15 H. Hu, B. Jiang, H. Wu, J. Zhang and X. Chen, J. Environ. Radioact., 2016, 165, 39-46.

$16 \mathrm{H}$. Hu, B. Jiang, J. Zhang and X. Chen, RSC Adv., 2015, 5, 104769-104778.

17 P. Rajec, O. Rosskopfova, M. Galambos, V. Fristak, G. Soja, A. Dafnomili, F. Noli, A. Dukic and L. Matovic, J. Radioanal. Nucl. Chem., 2016, 310, 253-261.

18 P. Rajec, M. Galambos, M. Dano, O. Rosskopfova, M. Caplovicova, P. Hudec, M. Hornacek, I. Novak, D. Berek and L. Caplovic, J. Radioanal. Nucl. Chem., 2015, 303, 277286.

19 W. R. Wilmarth, G. J. Lumetta, M. E. Johnson, M. R. Poirier, M. C. Thompson, P. C. Suggs and N. P. Machara, Solvent Extr. Ion Exch., 2011, 29, 1-48.

20 C. Nash, B. Musall, M. Morse and D. McCabe, Sep. Sci. Technol., 2015, 50, 2881-2887.

21 P. Xiao, D. Han, M. L. Zhai, L. Xu and H. B. Li, J. Hazard. Mater., 2017, 324, 711-723.

22 J.-H. Zu, Y.-Z. Wei, M.-S. Ye, F.-D. Tang, L.-F. He and R.-Q. Liu, Nucl. Sci. Tech., 2015, 26, 69-75.

23 B. Gierczyk, M. Ceglowski and M. Zalas, PLoS One, 2015, 10, e0122891.

24 D. Han, X. Li, J. Peng, L. Xu, J. Li, H. Li and M. Zhai, RSC Adv., 2016, 6, 69052-69059.

$25 \mathrm{~J} . \mathrm{Zu}, \mathrm{M}$. Ye, P. Wang, F. Tang and L. He, RSC Adv., 2016, 6, 18868-18873.

26 W. Luo, A. Inoue, T. Hirajima and K. Sasaki, Appl. Surf. Sci., 2017, 394, 431-439.

27 M. Petrova, M. Guigue, L. Venault, P. Moisy and P. Hesemann, Phys. Chem. Chem. Phys., 2015, 17, 1018210188.

28 B. H. Gu, G. M. Brown, P. V. Bonnesen, L. Y. Liang, B. A. Moyer, R. Ober and S. D. Alexandratos, Environ. Sci. Technol., 2000, 34, 1075-1080.

29 D. Jermakowicz-Bartkowiak and B. N. Kolarz, React. Funct. Polym., 2011, 71, 95-103.

30 D. Pan, G. Ye, F. Wang and J. Chen, Prog Chem., 2012, 24, 2167-2176.

31 S. Tachimori, S. Suzuki and Y. Sasaki, J. At. Energy Soc. Jpn., 2001, 43, 1235-1241.

32 J. Y. Yuan, D. Mecerreyes and M. Antonietti, Prog. Polym. Sci., 2013, 38, 1009-1036.

33 J. Y. Yuan and M. Antonietti, Polymer, 2011, 52, 1469-1482. 
34 L. C. Tome and I. M. Marrucho, Chem. Soc. Rev., 2016, 45, 2785-2824.

35 Y. Jiang, F. Li, G. Ding, Y. Chen, Y. Liu, Y. Hong, P. Liu, X. Qi and L. Ni, J. Colloid Interface Sci., 2015, 455, 125-133.

36 Z. Dong, J. Z. Liu, W. J. Yuan, Y. P. Yi and L. Zhao, Chem. Eng. J., 2016, 283, 504-513.

37 J. Chen, Y. Y. Ao, T. R. Lin, X. Yang, J. Peng, W. Huang, J. Q. Li and M. L. Zhai, Polymer, 2016, 87, 73-80.

38 S. Milicevic, L. Matovic, D. Petrovic, A. Aukic, V. Milosevic, D. Dokic and K. Kumric, J. Radioanal. Nucl. Chem., 2016, 310, 805-815.
39 J. Behnsen and B. Riebe, Appl. Geochem., 2008, 23, 27462752.

40 R. Konasova, J. J. Dytrtova and V. Kasicka, J. Sep. Sci., 2016, 39, 4429-4438.

41 H. Demey, T. Vincent, M. Ruiz, A. M. Sastre and E. Guibal, Chem. Eng. J., 2014, 244, 576-586.

42 D. Liping, S. Yingying, S. Hua, W. Xinting and Z. Xiaobin, J. Hazard. Mater., 2007, 143, 220-225. 